\title{
UJI DAYA HAMBAT EKSTRAK DAN FRAKSI SPONS Aaptos Aaptos TERHADAP PERTUMBUHAN Escherichia coli, Staphylococcus aureus, dan Candida albicans
}

\author{
Sitti Nurhaliza Tunggali ${ }^{1)}$, Herny E. I. Simbala ${ }^{1)}$, Henki Rotinsulu ${ }^{1)}$ \\ ${ }^{1)}$ Program Studi Farmasi FMIPA UNSRAT Manado, 95115
}

\begin{abstract}
Sponge Aaptos aaptos is a marine biota that has great potential, which can be applied, in the pharmaceutical field because of the presence of large compounds in inhibiting microbial growth. This study aims to determine the inhibitory activity of extracts and fractions of sponge Aaptos aaptos on microbial growth of Escherichia coli, Staphylococcus aureus, and Candida albicans. The samples were extracted by maceration with $96 \%$ ethanol and fractioned with n-hexane, choloroform and methanol. Testing is done using the Disc Diffusion Agar method. Crude ethanol extract and fraction of sponge Aaptos aaptos showed the greatest antimicrobial activity against Staphylococcus aureus and categorized as strong, with an average value of $20.32 \mathrm{~mm}$ for ethanol extract with strong categories, chloroform fraction 13,28 $\mathrm{mm}$ with medium category and methanol fractions $18,48 \mathrm{~mm}$ strong category.
\end{abstract}

Keyword: Aaptos aaptos, antimicrobial activity, Escherichia coli, Staphylococcus aureus, Candida albicans.

\begin{abstract}
ABSTRAK
Spons Aaptos aaptos merupakan biota laut yang memiliki potensi sebagai antimikroba yang dapat diterapkan di bidang farmasi dengan kandungan senyawa yang besar dalam menghambat pertumbuhan mikroba. Penelitian ini bertujuan untuk mengetahui aktivitas daya hambat dari ekstrak dan fraksi spons Aaptos aaptos terhadap pertumbuhan mikroba Escherichia coli, Staphylococcus aureus, dan Candida albicans. Sampel diekstraksi secara maserasi dengan etanol dan difraksinasi dengan pelarut n-heksan, kloroform dan metanol. Pengujian dilakukan dengan menggunakan metode Disc Diffusion Agar. Ekstrak kasar etanol dan fraksi dari Spons Aaptos aaptos menunjukkan aktivitas antimikroba paling besar terhadap Staphylococcus aureus dan dikategorikan kuat, dengan nilai rata - rata 20,32 mm untuk ekstrak etanol dengan kategori kuat, fraksi kloroform 13,28 mm, kategori sedang dan fraksi metanol 18,48 mm kategori kuat.
\end{abstract}

Kata Kunci : Aaptos aaptos, aktivitas antimikroba, Escherichia coli, Staphylococcus aureus, Candida albicans 


\section{PENDAHULUAN}

Spons adalah hewan metazoa multiseluler tergolong ke dalam filum Porifera, yang memiliki perbedaan struktur dengan metazoan lainnya. Spons mencari makan dengan menghisap dan menyaring air melalui seluruh permukaan tubuhnya secara aktif (Romimohtarto dan Juwana 1999). Spons terdiri dari 850 jenis, terbagi menjadi tiga kelas besar, yaitu Calcarea, Demospongiae dan Hexactinellida (Thakur dan Müller 2004).

Demospongiae merupakan jenis spons yang memiliki keanekaragaman tinggi sebagai kelas spons terbesar penghasil senyawa metabolit sekunder. Salah satu senyawa metabolit sekunder yang banyak diperoleh dari spons yaitu golongan alkaloid (Kumar dan Pal 2016). Salah satu jenis spons yang termasuk dalam kelas Demospongiae adalah jenis Spons Aaptos aaptos.

Spons Aaptos aaptos mempunyai morfologi yang berbentuk seperti spherical/subspherical (bundar/agak bundar), soliter, dan dengan permukaan yang halus atau berserabut (Ismet, 2007). Spons Aaptos aaptos menghasilkan metabolit sekunder yang mengandung senyawa bioaktif potensial. Senyawa-senyawa tersebut telah dibuktikan memiliki aktivitas sebagai antitumor, sehingga potensial sebagai sumber obatobatan baru (Pelletier et al., 1987).

$\begin{array}{clcr}\text { Spons } & \text { Aaptos aaptos dapat } \\ \text { menghasilkan } & \text { senyawa } & \text { khusus } & \text { yaitu }\end{array}$ Aaptamine yang dapat digunakan dalam bidang farmasi. Menurut hasil penelitian dari Yu et al., (2014) berhasil mengisolasi turunan Aaptamin dari Spons Aaptos aaptos yang memiliki aktivitas sebagai antifungi dan antiHIV-1. Penelitian yang dilakukan oleh Kardono (2006) dan Sussana (2006) bahwa jenis spons Aaptos aaptos memiliki potensi sebagai senyawa antibakteri.
Berdasarkan latar belakang tersebut di atas peneliti akan melakukan penelitian terhadap uji daya hambat ekstrak dan fraksi Spons Aaptos aaptos terhadap pertumbuhan Escherichia coli, Staphylococcus aureus dan Candida abicans.

\section{METODE PENELITIAN Bentuk Penelitian}

Penelitian ini merupakan penelitian dengan menggunakan metode eksperimental laboratorium yang akan menguji daya hambat ekstrak dan fraksi dari Spons Aaptos aaptos.

\section{Waktu dan Tempat Penelitian}

Penelitian ini di laksanakan pada bulan Oktober 2018 - Februari 2019. Tempat pengambilan sampel dilakukan di Perairan Selat Lembeh, Kota Bitung dan untuk preparasi sampel, pengamatan dilakukan di Laboratorium Penelitian Farmasi Lanjutan (Farmakognosi Fitokimia dan Laboratorium Mikrobiologi Farmasi) Program Studi Farmasi, Fakultas Matematika dan Ilmu Pengetahuan Alam, Universitas Sam Ratulangi.

\section{Alat dan Bahan}

a. Alat

Alat yang digunakan dalam penelitian ini yaitu scuba diving, sarung tangan, zipper bag, gunting, kamera, wadah kaca, pisau, Erlenmeyer (Pyrex), corong pisah, timbangan analitik, gelas ukur (Pyrex), gelas kimia (Pyrex), cawan petri, autoklaf (autoklaf KT-30s), spatula, pinset, pembakar spritus, pipet tetes, mikro tubes, batang pengaduk, Laminary air flow (Clean Bench), rak tabung reaksi, tabung reaksi, lemari pendingin, incubator incucell ( $\mathrm{N}$ - Biotek), cakram (paper disc), mikropipet, digital caliper, vial, oven, jarum ose, vortex dan jas lab 


\section{b. Bahan}

Bahan yang digunakan yaitu Spons Aaptos aaptos, bakteri Escherichia coli ATCC 25922, bakteri Staphylococcus aureus ATCC 25923, dan jamur Candida albicans ATCC 10231, etanol 96\%, aquadest, metanol, n-heksan, kloroform, Pepton, Ekstrak Beef, $\mathrm{NaCl}$, Agar, Paper Disc, Kloramfenikol Paper Disc, label, spidol permanen, tissue, aluminium foil, kertas saring, dan kapas.

\section{Prosedur Penelitian}

\section{Ekstraksi}

Spons Aaptos aaptos sebanyak $1660 \mathrm{~g}$ diekstrak dengan cara maserasi. Sampel dibersihkan dari bahan pengotor, dipotong kecil - kecil dimasukkan ke dalam wadah, kemudian direndam dengan pelarut etanol 96\% sampai sampel terendam semuanya, dikocok- kocok lalu dibiarkan selama 1x24 jam. Sampel yang sudah direndam kemudian disaring menggunakan corong dan kertas saring dan menghasilkan filtrat 1 dan debris 1 . Debris 1 direndam kembali dengan etanol 96\% sampai terendam semuanya, debris dikocok - kocok dan dimaserasi selama 1x24 jam. Diulangi cara yang sama sampai memperoleh 3 filtrat dan 3 debris. Campurkan filtrat 1, 2, dan 3 yang diperoleh menjadi satu. Filtrat dievaporasi menggunakan oven dengan suhu $40^{\circ} \mathrm{C}$ hingga memperoleh ekstrak kasar spons Aaptos aaptos dan timbang dengan menggunakan timbangan analitik. Ekstrak kasar etanol spons Aaptos aaptos sebanyak 28,81 g, selanjutnya ekstrak kasar etanol digunakan dalam fraksinasi dan pengujian daya hambat antimikroba.

\section{Fraksinasi}

Ekstrak kasar etanol Spons Aaptos aaptos sebanyak 10,00 g dimasukkan dalam Erlenmeyer, dilarutkan dengan campuran metanol : air (MeOH : $\left.\mathrm{H}_{2} \mathrm{O}\right)$ (80:20) sebanyak $100 \mathrm{~mL}$. Setelah sampel larut, dimasukkan ke dalam corong pisah lalu ditambahkan pelarut n-heksan dengan jumlah yang sama, setelah itu dikocok berulangkali sampai homogen. Dibiarkan sampai terbentuk dua lapisan metanol : air $\left(\mathrm{MeOH}: \mathrm{H}_{2} \mathrm{O}\right)$ dan n- heksan. Masing-masing lapisan ditampung dalam wadah yang berbeda. Lapisan n-heksan dievaporasi menggunakan oven hingga kering, lalu ditimbang dengan timbangan analitik dan diperoleh fraksi $\mathrm{n}$-heksan $0,1 \mathrm{~g}$.

Lapisan $\mathrm{MeOH}: \mathrm{H}_{2} \mathrm{O}$ ditambahkan akuades sebanyak $100 \mathrm{~mL}$ dipartisi dengan pelarut kloroform dengan perbandingan 1:1 v/v dalam corong pisah, lalu dikocok berulangkali sampai homogen. Dibiarkan sampai terbentuk dua lapisan yaitu lapisan $\mathrm{MeOH}$ dan kloroform. Masing - masing lapisan ditampung dalam wadah yang berbeda. Lapisan kloroform dievaporasi menggunakan oven hingga kering lalu ditimbang dan diperoleh fraksi kloroform 8,8 g. Lapisan $\mathrm{MeOH}$ yang ditampung pada wadah yang lain dievaporasi menggunakan oven hingga kering lalu ditimbang berat sampel, dan diperoleh fraksi $\mathrm{MeOH}$ 9,3 g. Ketiga fraksi digunakan dalam pengujian aktivitas antimikroba dan dihitung nilai rendemen dengan persamaan sebagai berikut:

$$
\begin{aligned}
& \text { Rendemen } \\
& =\frac{\text { Berat Fraksi }}{\text { Berat ekstrak }} \times 100 \% \ldots \ldots \ldots \text {..... persamaan } 1
\end{aligned}
$$

\section{Sterilisasi Alat}

Alat-alat yang digunakan dalam penelitian uji daya hambat ini disterilkan terlebih dahulu. Alat-alat gelas disterilkan menggunakan autoklaf pada suhu $121{ }^{\circ} \mathrm{C}$ selama 15 menit, pinset dibakar dengan pembakaran di atas api langsung dan media disterilkan menggunakan autoklaf pada suhu $121{ }^{\circ} \mathrm{C}$ selama 15 menit (Ortez, 2005). 


\section{Pembuatan Media Cair B1}

Ditimbang Pepton 0,5 g, ekstrak daging 0,3 g (meat extract), Natrium klorida $0,3 \mathrm{~g}$ dilarutkan dalam akuades sebanyak 100 $\mathrm{mL}$ menggunakan Erlenmeyer, dikocok sampai homogen. Media yang telah homogen kemudian disterilkan dengan menggunakan autoklaf pada suhu $121^{\circ} \mathrm{C}$ selama 15 menit. Dipipet $1 \mathrm{~mL}$ media cair B1, kemudian masukkan dalam tabung reaksi dan tutup dengan aluminium foil. Media cair B1 siap digunakan sebagai media kultur mikroba (Ortez, 2005).

\section{Kultur Mikroba}

Masing - masing mikroba yang sudah dikultur (Escherichia coli, Staphylococcus aureus dan Candida albicans) ditambahkan media cair B1 yang disiapkan sebelumnya sebanyak $100 \mu \mathrm{L}$ kedalam tabung reaksi yang berbeda - beda. Masing - masing tabung reaksi ditutup dengan aluminium foil dan dimasukkan ke dalam inkubator selama 1x24 jam dengan suhu $37^{\circ} \mathrm{C}$ (Ortez, 2005).

\section{Pembuatan Kontrol (Postitif dan Negatif)}

Kontrol postif yang digunakan yaitu Kloramfenikol Paper Disc dan Kontrol negatif yang digunakan dalam penelitian ini yaitu menggunakan metanol, dengan cara membuat larutan stok metanol dengan mengambil sebanyak $200 \mu \mathrm{l}$ metanol kemudian ditotolkan pada paper disc.

\section{Pembuatan Larutan Uji}

Sebanyak $1 \mathrm{mg}$ ekstrak kasar spons Aaptos aaptos dilarutkan dalam $200 \mu \mathrm{L}$ metanol sehingga menghasilkan konsentrasi larutan uji sebesar $250 \mu \mathrm{g} / 50 \mu \mathrm{L}$ (Ortez, 2005). Perlakuan yang sama dilakuakan untuk fraksi metanol, fraksi kloroform dan fraksi nheksan.

\section{Pembuatan Media Agar B1}

Pepton 0,5 g, ekstrak daging (meat extract) $0,3 \mathrm{~g}$, natrium klorida $0,3 \mathrm{~g}$, nutrient agar 1,5 g dan dilarutkan dalam akuades sebanyak $100 \mathrm{~mL}$ menggunakan Erlenmeyer, dikocok sampai homogen. Media yang telah homogen kemudian disterilkan dengan menggunakan autoklaf pada suhu $121^{\circ} \mathrm{C}$ selama 15 menit. Media agar B1 siap digunakan untuk uji aktivitas antimikroba (Ortez, 2005).

\section{Pengujian Aktivitas Antimikroba}

Metode yang digunakan yaitu Metode Difusi (Disc Diffusion Kirby and Bauer). Pengujian aktivitas antimikroba ini cakram (paper disc) yang digunakan berukuran $6 \mathrm{~mm}$ dengan daya serap $50 \mu \mathrm{L}$ tiap cakram. Diinokulasi suspensi mikroba dalam media dan dihomogenkan. Media yang sudah diinokulasi mikroba dituangkan dalam cawan petri sampai media memadat, kemudian cawan petri diberi label Sampel yang telah ditentukan kosentrasinya $(250 \mu \mathrm{g} / 50 \mu \mathrm{L})$ ditotolkan pada masing-masing cakram dengan menggunakan mikropipet, kemudian diletakkan kertas cakram yang sudah ditotol ke dalam cawan petri dan diinkubasi 1 x 24 jam (Ortez, 2005).

\section{Pengamatan dan Pengukuran Zona Hambat}

Pengamatan dilakukan setelah 1x24 jam masa inkubasi. Daerah pada sekitaran cakram menunjukkan kepekaan mikroba terhadap antibiotik atau bahan antimikroba yang digunakan sebagai bahan uji yang dinyatakan dengan diameter zona hambat atau zona bening. Diameter zona hambat diukur dalam satuan millimeter ( $\mathrm{mm}$ ) menggunakan Digital Caliper dengan cara diukur diameter total zona bening cakram. Kemudian diameter 
zona hambat tersebut dikategorikan kekuatan daya anti bakterinya berdasarkan penggolongan Davis dan Stout (1971).

\section{HASIL DAN PEMBAHASAN}

\section{Ekstraksi dan Fraksinasi}

Sampel spons Aaptos aaptos yang dikoleksi dari perairan Selat Lembeh dipotong kecil-kecil, kemudian dimasukkan ke dalam wadah. Dipotong kecil-kecil untuk memperluas ukuran permukaan sampel, semakin luas permukaan sampel maka lebih banyak senyawa aktif akan tertarik dari sampel ke dalam pelarut (Kristanti et al., 2008).

Sampel spons Aaptos aaptos selanjutnya diekstraksi dengan metode maserasi. Metode maserasi digunakan karena cara pengerjaanya yang mudah dikerjakan dengan menggunakan peralatan yang sederhana, tidak menggunakan pemanasan dan dapat menarik senyawa - senyawa aktif dari sampel dengan maksimal. Perendaman sampel dalam maserasi dapat membuat dinding sel dari sampel pecah dan membuat senyawa-senyawa yang ada dalam sampel yang terdapat dalam sitoplasma akan tertarik oleh pelarut. Dinding sel pecah di karenakan adanya perbedaan konsentrasi di dalam dan di luar sel. Konsentrasi di luar sel lebih tinggi dibandingkan konsentrasi di dalam sel yang rendah sehingga dinding sel pecah karena tidak bisa menahan tekanan dari perbedaan konsentrasi (Harborne, 1996).

Pada proses maserasi dilakukan pengocokan agar pelarut dapat melarut ke dalam sampel dan akan masuk ke ronggarongga sampel karena dalam keadaan diam selama maserasi menyebabkan turunnya perpindahan bahan aktif. Senyawa aktif dalam sampel agar tertarik semua ke dalam pelarut dilakukan remaserasi dengan penggantian pelarut sebanyak tiga kali dengan pelarut etanol. Maserasi agar lebih efisien dilakukan berulang kali dibandingkan hanya dilakukan sekali (Mujipradhana, 2018). Pelarut yang digunakan yaitu etanol, digunakan pelarut etanol 96\% karena didasarkan pada tingkat keamanan, kemudahan saat diuapkan, ekonomis, mudah bercampur dengan air serta sifatnya yang mampu melarutkan hampir semua zat, baik yang bersifat polar, semipolar, dan nonpolar (Sulastri et al., 2015).

Hasil ekstrak Spons Aaptos aaptos selanjutnya diuapkan menggunakan oven dengan suhu $40^{\circ} \mathrm{C}$, penguapan ekstrak ini dimaksudkan agar air dan pelarut yang tersisa dalam ekstrak akan menguap. Menggunakan suhu $40^{\circ} \mathrm{C}$ bertujuan untuk tetap menjaga senyawa bioaktif dalam filtrat karena biasanya senyawa-senyawa bioaktif rentan terhadap suhu tinggi (Kowal et al., 2018).

Hasil ekstrak kasar Spons Aaptos aaptos yang diperoleh selanjutnya di lanjutkan ke tahap fraksinasi. Fraksinasi yang digunakan yaitu fraksinasi cair - cair berdasarkan perbedaan tingkat kepolaran yaitu dimulai dari pelarut n-heksan, kloroform dan metanol. Pada proses fraksinasi dilakukan pengocokan sebelum memperoleh 2 lapisan hal ini bertujuan agar kandungan kimia yang terdapat dalam Spons Aaptos aaptos secara selektif dapat ditarik oleh pelarut yang digunakan (Wewengkang et al., 2014). Pada saat penyarian dengan pelarut - pelarut berdasarkan tingkat kepolaran akan terbentuk 2 lapisan, pelarut dengan massa jenis lebih tinggi berada di lapisan bawah sedangkan pelarut dengan massa jenis lebih kecil berada di lapisan atas.

Hasil rendemen yang diperoleh dari ekstrak dan fraksi Spons Aaptos aaptos menggunakan pelarut Etanol, n-heksan, kloroform dan metanol dapat dilihat pada tabel 1 dibawah ini. 
Tabel l. Rendemen ekstrak dan fraksi Spons Aaptos aaptos

\begin{tabular}{|c|c|c|c|}
\hline No. & Sampel & Randemen (\%) & Warna Sampel \\
\hline $\mathbf{l .}$ & EE & 1,74 & Coklat \\
\hline $\mathbf{2 .}$ & FN & 1,00 & Kuning Terang \\
\hline $\mathbf{3 .}$ & FK & 88,00 & Kuning kecoklatan \\
\hline $\mathbf{4 .}$ & FM & 93,00 & Hitam \\
\hline
\end{tabular}

Keterangan :

EKE : Ekstrak Kasar Etanol

FK : Fraksi Kloroform

FM : Fraksi Metanol

FN : Fraksi n-Heksan

Sampel ekstrak etanol warna yang dihasilkan yaitu warna coklat dan massa ekstrak yang diperoleh $28,81 \mathrm{~g}$ dari massa awal sampel $1660 \mathrm{~g}$ dengan nilai rendemen $1,74 \%$. Jumlah ekstrak etanol yang akan digunakan untuk pengujian aktivitas antimikorba sebanyak 10,00 g ekstrak kasar etanol spons Aaptos aaptos di fraksinasi dengan metanol air kemudian dipartisi dengan pelarut $\mathrm{n}$ - heksan menghasilkan 2 lapisan, yaitu lapisan $\mathrm{n}$ - heksan dan lapisan metanol. Warna yang dihasilkan dari filtrat fraksi $n-$ heksan yaitu kuning terang dan massa ekstrak yang diperoleh $0,1 \mathrm{~g}$ dari massa awal sampel $10,00 \mathrm{~g}$ dengan nilai rendemen yang diperoleh $1,00 \%$. Lapisan metanol dipartisi kembali dengan pelarut kloroform sampai menghasilkan 2 lapisan yaitu lapisan kloroform dan lapisan metanol. Warna dari filtrat kloroform yaitu kuning kecoklatan dan massa ekstrak yang diperoleh yaitu $8,8 \mathrm{~g}$ dari massa awal sampel 10,00 g dengan nilai rendemen $88 \%$. Untuk lapisan metanol filtrat yang dihasilkan berwarna hitam dan massa ektrak yang diperoleh yaitu 9,3 g dari massa awal sampel 10,00 g dengan nilai rendemen $93 \%$.

Nilai rendemen yang dihasilkan berbeda karena perbedaan tingkat kepolaran dari masing - masing pelarut. Terlihat dari hasil rendemen yang dihasilkan fraksi metanol lebih tinggi hasil rendemenya yaitu $93 \%$. Hal ini dikarenakan pelarut metanol mampu mengekstrak lebih banyak senyawa senyawa aktif dari sampel sehingga senyawa - senyawa aktif yang terdapat pada spons Aaptos aaptos lebih bersifat polar. Hal ini sesuai yang dinyatakan Priyanto (2012), bahwa rendemen ekstrak hasil maserasi dengan pelarut yang berbeda akan menghasilkan rendemen yang berbeda dan nilai rendemen yang dihasilkan dari ekstrak metanol diduga dipengaruhi sifat larutan tersebut yang dapat melarutkan hampir semua komponen bahan aktif.

\section{Uji Aktivitas Antimikroba Spons Aaptos aaptos}

Pengujian aktivitas antimikroba dari spons Aaptos aaptos dilakukan pada bakteri Escherichia coli mewakili bakteri Gram negatif, bakteri Staphylococcus aureus yang mewakili bakteri Gram positif dan Candida albicans yang mewakili Jamur menggunakan Metode difusi agar (difusi Kirby-Bauer yang telah dimodifikasi). Masing - masing ekstrak kasar, fraksi $\mathrm{n}$ - heksan, fraksi kloroform dan fraksi metanol diujikan pada masing - masing bakteri dan jamur. Metode difusi digunakan karena prosedurnya yang sederhana, mudah dan praktis untuk dikerjakan (Mpila, 2012).

Penggunaan mikroba hal ini bertujuan melihat apakah ekstrak dan fraksi spons Aaptos aaptos memiliki aktivitas antimikroba terhadap mikroba patogen pada tubuh manusia dan untuk mengetahui spektrum dari aktivitas antimikroba spons Aaptos aaptos memiliki spektrum luas (membunuh banyak jenis mikroba) atau spektrum sempit (membunuh salah satu mikroba).

Hasil yang diperoleh dalam uji aktivitas antimikroba dilakukan pengamatan selama 1x24 jam masa inkubasi dengan $3 \mathrm{kali}$ penggulangan untuk masing - masing mikroba. Aktivitas yang terbentuk terlihat 
dari adanya zona hambat (zona bening) di sekitaran cakram dengan ukuran cakram (paper disc) $6 \mathrm{~mm}$, membuktikan bahwa ekstrak dan fraksi spons Aaptos aaptos yang diujikan menunjukkan kepekaan terhadap masing - masing mikroba dan antibiotik yang digunakan sebagai kontrol positif. Konsentrasi yang digunakan $250 \mu \mathrm{g}$, dengan daya serap masing- masing paper disc $50 \mu \mathrm{L}$. Hasil pengukuran diameter zona hambat ekstrak Kasar, Fraksi n - heksan fraksi kloroform dan fraksi metanol Spons Aaptos aaptos terhadap bakteri Escherichia coli, Staphyloccocus aureus, dan Candida albicans disajikan pada tabel 2 dibawah ini.

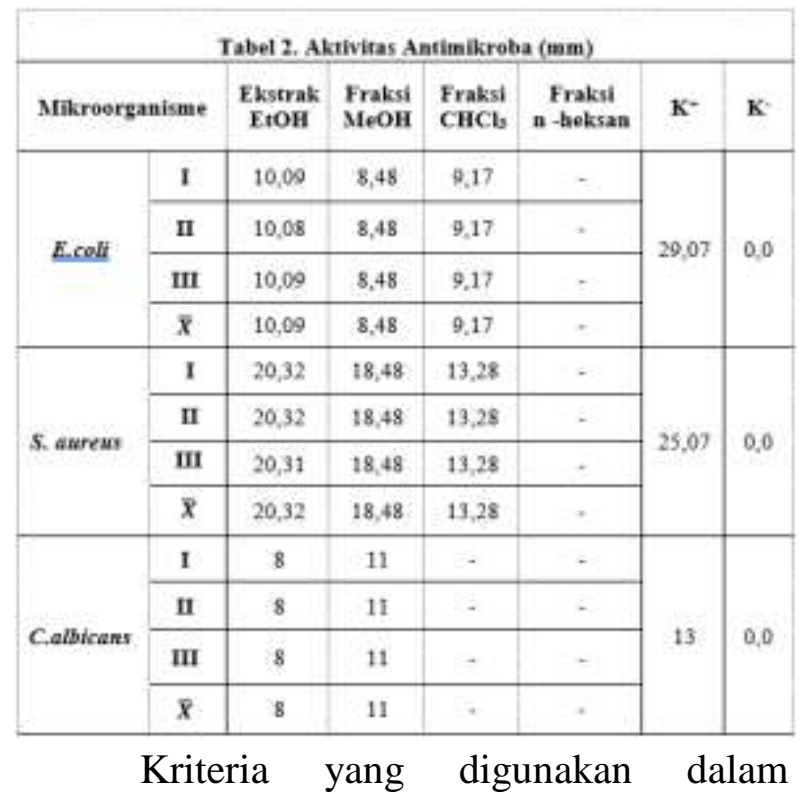
penelitian ini untuk menggolongkan daya hambat dari kontrol uji dan bahan uji Spons Aaptos aaptos menggunkana kriteria kekuatan antibakteri menurut Davis dan Stout yaitu dapat dilihat pada tabel 3 dibawah ini:

Tabel 3. Standar Kekuatan Daya Antimikroba

\begin{tabular}{c|c}
\hline $\begin{array}{c}\text { Diameter Zona } \\
\text { Bening }(\mathbf{m m})\end{array}$ & Kategori \\
\hline$>20$ & Sangat Kuat \\
\hline $10-20$ & Kuat \\
\hline $5-10$ & Sedang \\
\hline$<5$ & Lemah \\
\hline
\end{tabular}

Kontrol negatif yang digunakan yaitu metanol, terlihat dari hasil yang di peroleh metanol tidak menunjukkan adanya zona hambat pada pengujian yang dilakukan pada masing - masing mikroba uji. Hal ini sesuai dengan penelitian yang dilakukan oleh Wewengkang et al., (2014) dan Mujipradhana, (2018) membuktikan bahwa kontrol negatif metanol yang digunakan tidak berpengaruh pada uji antimikroba, sehingga daya hambat yang terbentuk tidak dipengaruhi oleh pelarut melainkan karena aktivitas senyawa yang ada dalam Spons Aaptos aaptos.

Kontrol positif yang digunakan yaitu kloramfenikol. Menggunakan kloramfenikol dikarenakan kloramfenikol merupakan antibiotik berspektrum luas. Hasil yang diperoleh bahwa pada bakteri Escherichia coli menghasilkan daya hambat yang besar ditunjukkan dengan hasil yang diperoleh yaitu 29,07 mm dibandingkan dengan bakteri Staphylococcus aureus dan Candida albicans. Hal ini dikarenakan antibiotik kloramfenikol lebih peka terhadap bakteri Escherichia coli (Gram negatif), kloramfenikol hanya membutuhkan konsentrasi $0,2-5 \mu \mathrm{g} / \mathrm{mL}$, sedangkan pada kebanyakan bakteri gram positif bakteri dihambat pada konsentrasi 1-10 $\mu \mathrm{g} / \mathrm{mL}$ (Katzung, 2004).

Hasil ekstrak kasar etanol, fraksi kloroform dan fraksi metanol Spons Aaptos aaptos, dari semua mikroba uji yaitu Escherichia coli, Staphylococcus aureus dan Candida albicans, terlihat yang memberikan daya hambat yang paling besar terdapat pada bakteri Staphylococcus aureus dengan jumlah rata - rata ekstrak kasar yaitu 20,32 mm dengan kategori kuat, fraksi kloroform 13,28 mm kategori sedang dan fraksi metanol 18,48 mm dengan kategori kuat. Hal ini menunjukkan bahwa ekstrak dan fraksi dari spons Aaptos aaptos memiliki daya hambat yang lebih peka pada Staphylococcus aureus 
dibandingkan Escherichia coli dan Candida albicans. Hasil ini juga sesuai dengan yang dinyatakan Murniasih (2003), bahwa spons Aaptos aaptos memiliki senyawa alkaloid yaitu Aaptamine dan Demethylaaptamine yang mempunyai keaktifan menghambat pertumbuhan bakteri Staphylococcus aureus. Bakteri gram positif cenderung lebih sensitif terhadap antimikroba, karena struktur dinding sel bakteri gram positif lebih sederhana dibandingkan struktur dinding sel bakteri gram negatif sehingga memudahakan senyawa antimikroba untuk masuk kedalam sel bakteri gram positif.

Pada bakteri Escerichia coli hasil yang diperoleh paling efektif dari ekstrak kasar etanol, fraksi Kloroform dan fraksi metanol menunjukkan aktivitas antimikroba pada ekstrak kasar yaitu dengan rata - rata 10,09 $\mathrm{mm}$, fraksi metanol dengan rata - rata 8,48 $\mathrm{mm}$, dan fraksi kloroform dengan rata - rata 9,17 mm. ketiga fraksi termasuk dalam kategori lemah. Perbedaan sensitifitas bakteri Gram positif dan bakteri Gram negatif dapat disebabkan oleh perbedaan struktur dinding sel yang dimiliki oleh masing-masing bakteri seperti peptidoglikan, jumlah lipid dan aktivitas enzim. Ini sesuai dengan penelitian Renhoran (2012) yang menyatakan bahwa Gram negatif cenderung bersifat sensitif terhadap antimikroba yang bersifat polar.

Fraksi n-heksan tidak menunjukkan adanya zona hambat atau zona bening yang terbentuk disekitran paper disc pada semua mikroba uji yaitu Escherichia coli, Staphylococcus aureus dan Candida albicans. Pada bakteri Candida albicans fraksi kloroform juga tidak menunjukkan terbentuknya zona hambat hal ini di sebabkan karena pada fraksi $\mathrm{n}$ - heksan dan kloroform pada bakteri Candida albicans tidak memiliki senyawa spesifik yang dapat menghambat semua mikroba uji.
Hasil fraksi ekstrak kasar etanol dan fraksi metanol pada jamur Candida albicans menunjukkan memiliki aktivitas antimikroba cenderung sensitif terhadap senyawa yang bersifat polar, terlihat adanya zona hambat yang terbentuk yang dikategorikan lemah dan sedang yaitu nilai rata - rata $8,00 \mathrm{~mm}$ dan $11,00 \mathrm{~mm}$.

Perbedaan hasil aktivitas dari ekstrak dan fraksi dari Spons Aaptos aaptos terhadap mikroba uji selain senyawa yang terkandung dalam sampel dan kepekaan dari masing masing Gram positif dan Gram negatif juga di pengaruhi oleh faktor lingkungan (habitat) dan lokasi pengambilan sampel. Bell dan Barnes (2003) juga menyatakan bahwa substrat tumbuh spons dapat berpengaruh terhadap morfologi spons, yang dengan demikian juga akan mempengaruhi bioaktivitasnya.

\section{KESIMPULAN}

Hasil penelitian yang diperoleh menunjukkan bahwa ekstrak kasar dan fraksi dari Spons Aaptos aaptos memiliki aktivitas antimikroba karena mampu menghambat pertumbuhan mikroba uji Staphylococcus aureus dengan zona hambat yang dapat dikategorikan kuat. Nilai rata-rata dari aktivitas antimikroba ekstrak kasar etanol adalah 20,32 mm dengan kategori kuat, untuk fraksi kloroform 13,28 mm dengan kategori sedang dan fraksi metanol 18,48 $\mathrm{mm}$ dengan kategori kuat.

\section{SARAN}

Perlu dilakukan penelitian lebih lanjut terhadap Spons Aaptos aaptos ke uji aktivitas lainnya agar dapat mengetahui manfaat lain selain aktivitas antimikroba.

\section{DAFTAR PUSTAKA}


Bell JJ, DKA Barnes. 2003. Effects of disturbance on assemblages: an example using Porifera. Biol Bull 205: 144-159.

Davis, W.W., Stout, T.R. 1971. Disc plate method of microbiological assay. Journal of microbiology. 22(4):659-665.

Harborne, J. B. 1996. Metode Fitokimia: Penentuan Cara Modern Menganalisis Tumbahan. Diterjemahkan oleh Kosasih Padmawinata dan Iwang Soediro. ITB, Bandung.

Ismet. 2007. Penapisan Senyawa Bioaktif Spons Aaptos aaptos dan Petrosia sp. Dari lokasi yang berbeda. [Tesis]. Intitut Pertanian Bogor. Bogor.

Kardono K. 2006. Distribusi dan Preferensi Habitat Spons Kelas Demospongiae di Kepulauan Seribu Propinsi DKI Jakarta [Tesis]. Institut Pertanian Bogor, Bogor.

Katzung., Betram G. 2004. Farmakologi dasar dan klinik edisi 4. Alih Bahasa: staf dosen farmakolgi fakultas kedokteran unviversitas sriwijaya. EGC, Jakarta : 709-719

Kowal, A., Esther, A., Nickson, K., Kurniati, K., Henky, M., Deiske, H. 2018. Potensi antibakteri karang lunak lobophytum sp. Dari perairan pangalisang pulau bunaken terhadap bakteri Pseudomonas aeruginosa dan Staphylococcus aureus. Jurnal Ilmiah Platax. 6(2)

Kristanti, A. N., N.S. Aminah., M. Tanjung., B. Kurniadi. 2008. Buku Ajar Fitokimia. Unair Press, Surabaya.
Kumar, M. S., Pal, A. K. 2016. A review of Bioactive Compounds from Marine Organisms with Special Mention on the Potential of Marine Sponges in Pharmacological Applications. $J$. Mar. Biol. Ass. India. 58: 83-91.

Mpila, D. A. 2012. Uji Aktivitas Antibakteri Ekstrak Etanol Daun Mayana (Coleus atropurpureus benth) Terhadap Staphylococcus aureus, Escherichia coli dan Pseudomas aeruginosa Secara Invitro [skripsi]. Program Studi Farmasi FMIPA Universitas Sam Ratulangi, Manado.

Mujipradhana, V., Defny, W., Edi, S. Aktivitas antimikroba dari ekstrak ascidian herdmania momus pada mikroba patogen manusia. Jurnal Ilmiah Farmasi 7(3).

Murniasih, T. 2003. Metabolit Sekunder Dari Spons Sebagai Bahan Obat Obatan.Oseana. 28(3).

Ortez, J. H. 2005. Disk Diffusion testing in manual of antimicrobial susceptibility testing. Marie B. Coyle (Coord. Ed). American society for Microbiology, America.

Pelletier JC, MP Cava. 1987. Synthesis of the marine alkaloids aaptamine and demethyloxyaaptamine and of the parent structure didemethoxyaaptamien. $J \quad \mathrm{Org}$ Chem 52: 616-622.

Priyanto, R. A. 2012. Aktivitas Antioksidan Dan Komponen Bioaktif Pada Buah Bakau (Rhizophora mucronata Lamk.). [Skrips] Institut Pertanian Bogor. 
Renhoran, W. 2012. Aktivitas Antioksidan dan Mikrobiologi Ekstrak Sargassum polycystum [skripsi]. Departemen Teknologi Hasil Perairan Faklutas Perikanan dan Ilmu Kelautan IPB, Bogor.

Susanna. 2006. Kajian Kualitas Perairan Terhadap Kelimpahan dan Senyawa Bioaktif Antibakteri Spons Demospongiae di Kepulauan Seribu DKI Jakarta [Tesis]. Institut Pertanian Bogor, Bogor.

Sulastri, E., Cristadeolia, O., Yusriadi., 2015. Formulasi Mikroemulsi Ekstrak Bawang Hutan dan uji Aktivitas Antioksidan. Jurnal Pharmascience. 2(2):2

Thakur, N.L., Müller W.E.G. 2004.

Biotechnological potential of marine sponges. Current Science. 86(11).

Wewengkang, D., Deiske. S., Hengki. R. 2014. Karakterisasi dan bioaktif antibakteri senyawa spons Haliclona sp. dari teluk manado. Jurnal LPPM Bidang Sains dan Teknologi. 1(1).

Yu, H. B., Yang, F., Sun, F., Li, J., Jiao, W. H., Gan, J. H., Hu, W. Z., Lin, H. W. 2014. Aaptamine Derivatives with Antifungal and Anti-HIV-1 Activities from the South China Sea Sponge Aaptos aaptos. Mar. Drugs. 12: 6003-6013. 